\title{
A Validated Classification for External Immobilization of the Cervical Spine
}

\author{
Micha Holla $^{1}$ Joske M. R. Huisman ${ }^{1}$ Allard J. F. Hosman ${ }^{1}$ \\ ${ }^{1}$ Department of Orthopaedics, Radboud University Nijmegen Medical \\ Centre, Nijmegen, The Netherlands \\ Evid Based Spine Care J 2013;4:72-77. \\ Address for correspondence Micha Holla, MD, Department of \\ Orthopaedics, Radboud University Medical Centre, Postbox 357, Geert \\ Grooteplein 10, 6525GA Nijmegen, The Netherlands \\ (e-mail: Micha.Holla@radboudumc.nl).
}

\begin{abstract}
Keywords

- classification

- external

- cervical

- collars

- immobilizers

Study Design Interobserver and intraobserver reliability study. Objective The aim of this study is to validate a new classification system of external cervical spine immobilization devices by measuring the interobserver and intraobserver agreement.

Methods A classification system, with five main categories, based on the anatomical regions on which the device supports, was created. A total of 28 independent observers classified 50 photographs of different devices, designed to immobilize the cervical spine according to the new proposed classification system. At least 2 weeks later, the same devices were classified again in a new random order. Before and after the classification, all the participants answered questions about the usefulness of the proposed classification.

Results The mean interobserver and intraobserver agreement Fleiss' kappa was 0.88 and 0.91 , respectively. Both are, according to the interpretation described by Landis and Koch, "almost perfect." A majority of the participators answered that they needed a classification (89\%) and considered the classification to be clear (96\%). All the participants considered the classification to be useful in clinical practice.

Conclusion This study showed that the new classification of external cervical spine immobilizers, based on anatomical support areas, has an excellent interobserver and intraobserver agreement. Furthermore, the study participants considered the proposed classification to be clear and useful in clinical practice. As the majority of patients with cervical spine injuries are treated with external immobilization devices, this new classification system can improve the closed treatment of cervical spine injuries in daily clinical practice. Furthermore, it makes reproducible comparisons between groups possible, which are essential for further evolution of evidence-based spine care.
\end{abstract}

\section{Study Rationale and Context}

The majority of the cervical spine injuries are treated with some form of external immobilization. ${ }^{1}$ At this moment, there are more than hundreds of different external devices available to immobilize the cervical spine. These often prefabricated devices are made by a variety of manufacturers in an unregulated area of medical practice. ${ }^{2}$ No validated classifi- cation system for these devices is currently available. The diversity of specific names for all these different immobilizers can be confusing for the clinician and can cause misinterpretation. Furthermore, with the absence of a valid classification system, it is impossible to group these devices and report uniform data. The lack of comparable conservative treatment strategies is one of the major obstacles in gathering evidence- received

January 21, 2013

accepted after revision

July 18, 2013 (c) 2013 Georg Thieme Verlag KG Stuttgart · New York
DOI http://dx.doi.org/

$10.1055 / \mathrm{s}-0033-1357353$. ISSN 1663-7976. 


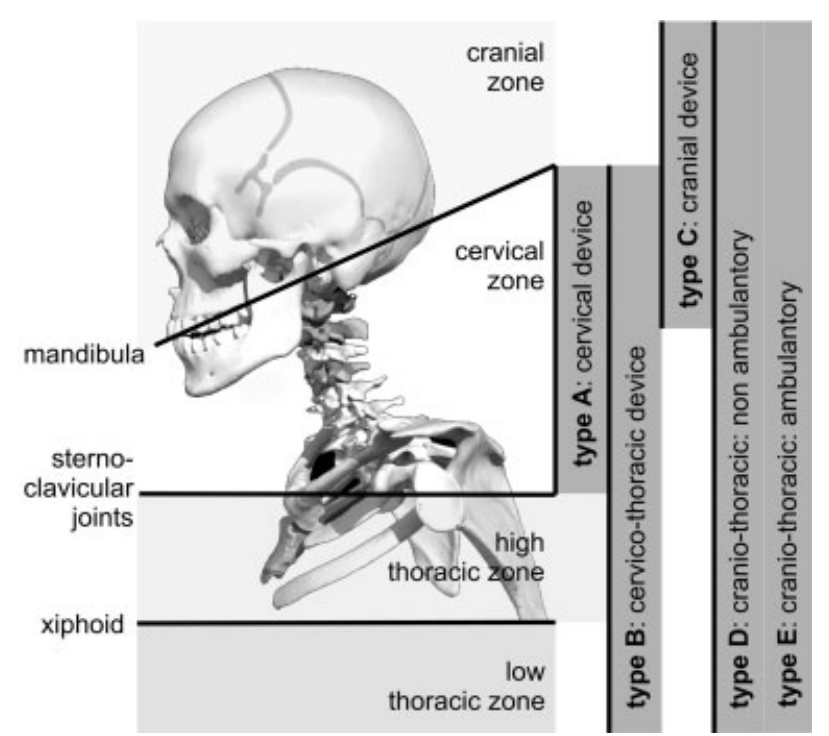

Fig. 1 Classification system for external cervical immobilization devices, based on the anatomical regions on which the device supports.

based treatments for cervical spine injuries. To solve this problem, we suggest to introduce a classification system for external cervical immobilization devices. The classification system is based on the anatomical regions on which the device supports. From a hypothetically biomechanical perspective, the more rigid the connection between two regions and the more distance of the spine is bridged, the better the device will restrict motion of the spine. Based on that principle, five main categories of devices were assigned: (1) type A, cervical; (2) type B, cervicothoracic; (3) type C, cranial; (4) type D, cranial thoracic for nonambulant patients; and (5) type E, cranial thoracic for ambulant patients (-Fig. 1). The subclassification is based on material and length of the immobilization device (-Fig. 2).

\section{Objective or Clinical Question}

The primary objective was to validate a new classification system for external cervical spine immobilization devices, based on anatomical support area, by measuring the interobserver and intraobserver agreement. The second objective was to assess the usefulness of the classification system according to different clinicians.

\section{Methods}

To determine the interobserver and intraobserver agreement, photographs of different external immobilizers of the cervical spine were classified by observers from different medical fields related to spine care. To assess the usefulness of the classification system, different clinicians answered a questionnaire.

- Classification system: The new classification system, as described above and depicted in - Figs. 1 and 2, was printed on hard copy cards for all observers.

- Selection of observers: A total of 28 healthcare workers, all related to trauma and spine care, participated in this study

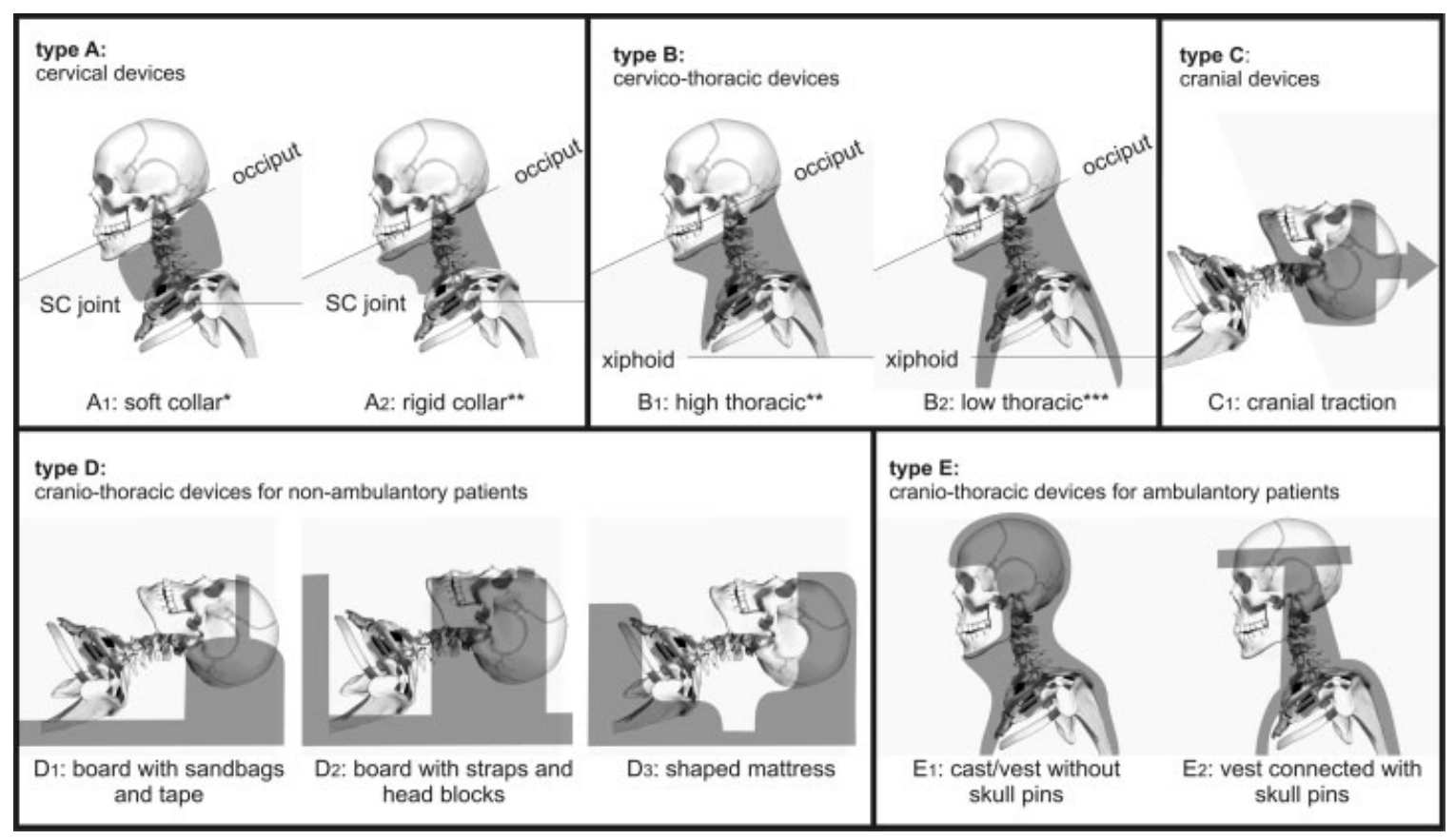

Fig. 2 Subclassification system based on the material properties and length of the immobilization device. * This device is composed of materials without any rigid components. ${ }^{*}$ If the device supports an anatomical border, its category is increased as follows: In case of doubt between type $A$ (cervical) or type B (cervicothoracic) device, the category is increased to type B1 (high cervicothoracic); in case of doubt between type B1 (high thoracic) or type B2 (low thoracic) device, the device is assigned to category B2 (low cervicothoracic device). ${ }^{* * *}$ A device that provides any support caudal to the xiphoid process is classified as a type B2 (low cervicothoracic) device. 
74 Validated Classification for External Immobilization of the Cervical Spine Holla et al.

Table 1 Medical profession of the participants

\begin{tabular}{|l|l|}
\hline Medical profession & $\begin{array}{l}\text { Number of } \\
\text { observers }\end{array}$ \\
\hline Orthopedic surgery & 2 \\
\hline Consultant & 2 \\
\hline Resident & 2 \\
\hline General surgery & 2 \\
\hline Consultant & \\
\hline Resident & 2 \\
\hline Intensive care & 2 \\
\hline Consultant & 4 \\
\hline Resident & \multicolumn{2}{|l}{} \\
\hline Nurse & 4 \\
\hline Emergency room & 4 \\
\hline Nurse & 4 \\
\hline Orthopedic appliance technicians & 28 \\
\hline Prehospital healthcare/ambulance personnel & \\
\hline Total number of observers &
\end{tabular}

as observers (-Table $\mathbf{1}$ ). To increase the clinical validity participants were selected from seven different medical professions, with different degrees of education. Apart from the information given on the hard copy card, none of the participants received additional information or education about the new classification system.

- Clinical usefulness: All participants anonymously answered a questionnaire about their judgment whether this classification system could be useful for their clinical practice (-Table $\mathbf{2}$ ).

- Selection of photographs and devices: Fifty photographs of different devices designed to immobilize the cervical spine were selected from Web sites of medical device manufactures and our own photo database (see Appendix 1 in online supplementary material). The photographs had to meet the following criteria: human adult, anterior-lateral view, daylight photograph, full-color, and relevant anatomy markers visible. Five devices of each category were present (-Fig. 3). The photographs were placed in a random order by Online Research Randomizer Form v4.0. ${ }^{3}$

- Assessment process: Based on the classification description as depicted in -Figs. $\mathbf{1}$ and $\mathbf{2}$, all the participants classified the 50 photographs independently without time limitation on a hard copy format. Before and after the classification of all devices, all participants anonymously answered the questionnaire about the clinical usefulness of the classification. After at least 2 weeks (mean: 20 days, range: 14-29 days), the same photographs in a different random order were again classified by the same participants. The observers did not have access to their earlier answers after they completed the forms. The observers were instructed not to communicate with other observers before and during the assessments. All data were blinded and collected by a research fellow.

- Analysis: For determination of the interobserver and intraobserver agreement, Fleiss' multirater free-marginal kappa was calculated based on a nominal scale with a qualitative variable using StatTools (Palisade Corporation, Ithaca, New York, United States). The kappa score was interpreted as described by Landis and Koch. ${ }^{4}$

\section{Results}

- Interobserver variability: The Fleiss' kappa value of the first round was 0.85 (95\% confidence interval [CI]: 0.85-0.86) and of the second round 0.91 (95\% CI: 0.91-0.92). The mean interobserver agreement of the two rounds was 0.88. The values per photograph are shown in -Table 3.

Table 2 Questionnaire related to the proposed classification

\begin{tabular}{|l|l|l|l|}
\hline Question & Answer & Yes & No \\
\hline Before classifying the devices & & $28(100 \%)$ & $0(0 \%)$ \\
\hline $\begin{array}{l}\text { Did you prescribe or apply an external cervical } \\
\text { spine immobilization device during the last year? }\end{array}$ & & $4(14 \%)$ & $24(86 \%)$ \\
\hline $\begin{array}{l}\text { Do you know a classification system for external } \\
\text { cervical spine immobilization devices? }\end{array}$ & & $25(89 \%)$ & $3(11 \%)$ \\
\hline $\begin{array}{l}\text { Are you in need for a valid classification system for } \\
\text { external cervical spine immobilization devices? }\end{array}$ & & $27(96 \%)$ & $1(4 \%)$ \\
\hline $\begin{array}{l}\text { Is the concept of the classification, as presented } \\
\text { in - Fig. 1, clear? }\end{array}$ & & $27(96 \%)$ & $1(4 \%)$ \\
\hline $\begin{array}{l}\text { Is the subclassification, as presented } \\
\text { in - Fig. 2, clear? }\end{array}$ & Too easy & Good & Too difficult \\
\hline After classifying the devices & $0(0 \%)$ & $28(100 \%)$ & $0(0 \%)$ \\
\hline $\begin{array}{l}\text { Do you think this classification is useful in clinical } \\
\text { practice? }\end{array}$ & & \\
\hline
\end{tabular}




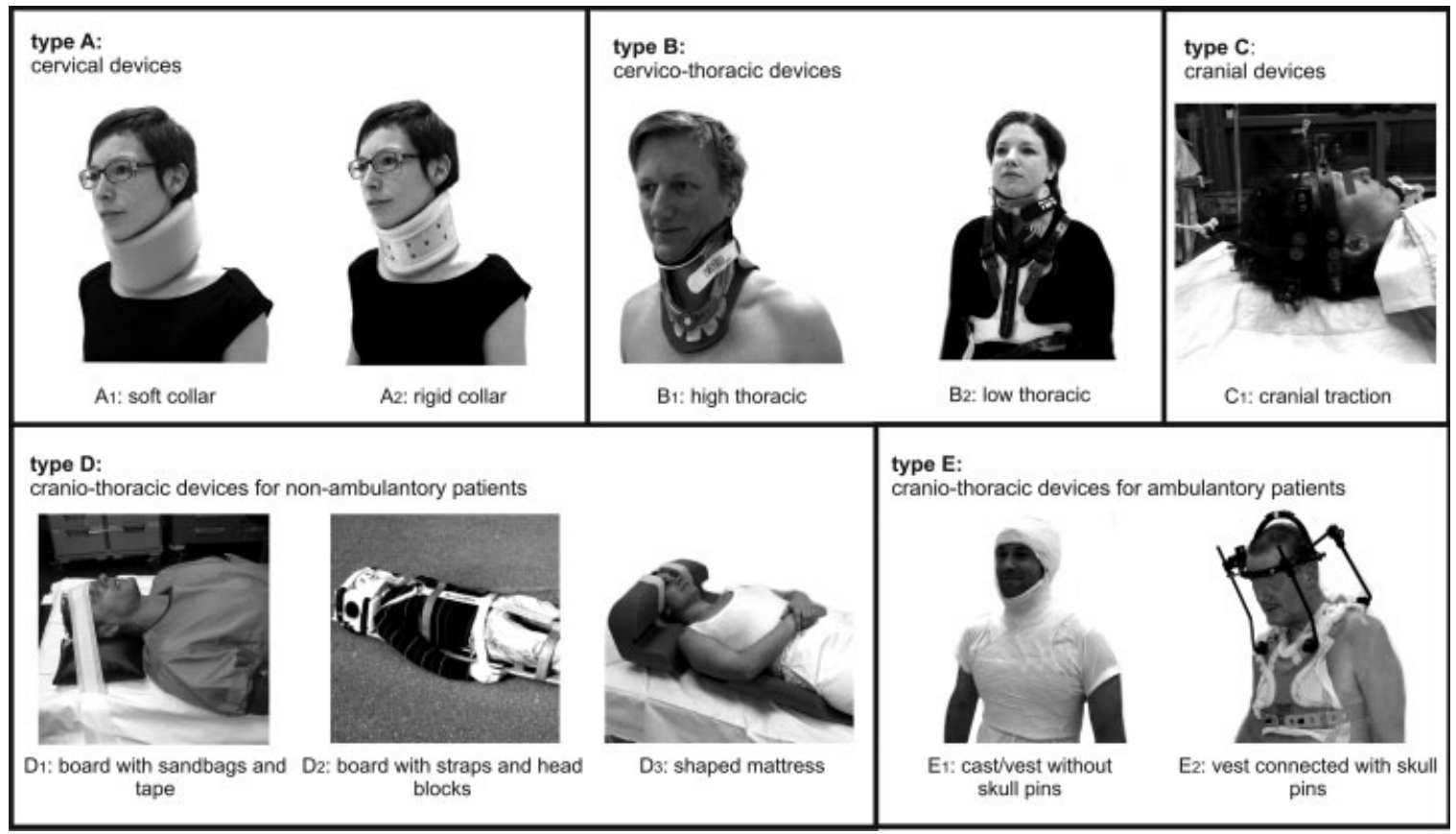

Fig. 3 Photographs of different cervical spine immobilizers.

- Intraobserver variability: The mean Fleiss' kappa value was 0.91 (range: 0.71-0.98, standard deviation: 0.06). The values per medical profession are shown in -Table 4. Except for one emergency room nurse (intraobserver agreement: 0.71 ), all participants scored an intraobserver agreement of 0.80 or higher.

- Clinical usefulness: The dichotomous and trichotomous results of the questions are presented in -Table 2. All observers $(100 \%)$ prescribed or applied one or more external immobilization devices during the last year. The vast majority of the participants (89\%) were in need for a validated classification system for external immobilization of the cervical spine. Four participants (14\%) reported to know a validated classification system. However, when asked to report what kind of classification they knew, no valid answer could be given. Before classification of the devices, most of the observers (96\%) found the classification and subclassification to be clear. After using the classification system, all participants (100\%) considered the classification system to be useful in clinical practice.

Table 3 Interobserver agreement kappa per subtype and photograph/device

\begin{tabular}{|l|l|l|l|l|l|l|l|}
\hline Type & Subtype & \multicolumn{4}{l|}{ Photograph } & \multicolumn{4}{l|}{ Mean } \\
\hline & & 1 & 2 & 3 & 4 & 5 & \\
\hline A: cervical & A1: soft collar & 1.00 & 1.00 & 1.00 & 1.00 & 100 & 1.00 \\
\hline & A2: rigid collar & 0.86 & 1.00 & 0.81 & 1.00 & 0.88 & 0.91 \\
\hline B: cervical thoracic & B1: high thoracic support & 0.70 & 0.81 & 0.68 & 0.84 & 0.73 & 0.75 \\
\hline & B2: low thoracic support & 0.88 & 0.95 & 0.98 & 0.82 & 0.91 & 0.91 \\
\hline C: cranial & C1: cranial traction & 0.98 & 0.98 & 1.00 & 1.00 & 0.97 & 0.99 \\
\hline D: cranial thoracic nonambulant & D1: board with sandbags & 0.97 & 0.98 & 0.98 & 1.00 & 0.96 & 0.98 \\
\hline & D2: board with head blocks & 1.00 & 1.00 & 1.00 & 1.00 & 1.00 & 1.00 \\
\hline & D3: shaped mattress & 1.00 & 1.00 & 1.00 & 0.97 & 0.96 & 0.99 \\
\hline E: cranial thoracic ambulant & E1: vest without scull pins & 0.91 & 0.68 & 1.00 & 0.79 & 0.72 & 0.82 \\
\hline & E2: vest with scull pins & 1.00 & 1.00 & 1.00 & 1.00 & 1.00 & 1.00 \\
\hline
\end{tabular}


Table 4 Intraobserver agreement kappa of the classification per profession

\begin{tabular}{|l|l|l|l|l|l|l|l|}
\hline & $\begin{array}{l}\text { Orthopedic } \\
\text { surgeons } \\
\text { and residents }\end{array}$ & $\begin{array}{l}\text { General surgeons } \\
\text { and residents }\end{array}$ & IC doctors & IC nurses & ER nurses & $\begin{array}{l}\text { Orthopedic } \\
\text { appliance } \\
\text { technicians }\end{array}$ & $\begin{array}{l}\text { Ambulance } \\
\text { personnel }\end{array}$ \\
\hline 1 & 0.98 & 0.93 & 0.80 & 0.82 & 0.71 & 0.89 & 0.96 \\
\hline 2 & 0.96 & 0.84 & 0.96 & 0.91 & 0.93 & 0.87 & 0.96 \\
\hline 3 & 0.96 & 0.93 & 0.93 & 0.89 & 0.93 & 0.93 & 0.96 \\
\hline 4 & 0.91 & 0.87 & 0.96 & 0.89 & 0.98 & 0.93 & 0.93 \\
\hline Mean & 0.95 & 0.89 & 0.91 & 0.88 & 0.89 & 0.91 & 0.95 \\
\hline
\end{tabular}

Abbreviations: ER, emergency room; IC, intensive care.

\section{Discussion}

- Findings from this study:

- Around $89 \%$ of the observers said they were in need for a classification for devices that immobilize the cervical spine.

- According to Landis and Koch, the interobserver and intraobserver agreement kappa values of this classification are rated "almost perfect."

- Approximately $96 \%$ of the observers rated the classification to be clear, probably due to the simplicity of the system.

- Previously published studies:

- At present there are no other validated classification systems for external cervical immobilization devices available.

- Strengths of this study:

- Introduction of a validated simple and clear classification system for external immobilizers of the cervical spine, considered useful in daily clinical practice by all observers.

- High validity due to 28 observers, from different medical backgrounds and, all related to trauma and spine care.

- Limitations:

- Although all observers rated this classification to be useful in clinical practice, this has not been proven by this study. Widespread implementation of this classification in clinical practice and research publications is needed to prove its usefulness in the future.

- This study shows excellent interobserver and intraobserver agreement results; however, it is not yet proven that this classification correlates with a different range of motion. Nonetheless, it is now possible to conduct systematic reviews, comparing different categories of immobilizers, and their ability to reduce cervical range of motion.

- Clinical relevance and impact: More than $65 \%$ of the cervical spine injuries are treated with external immobilization devices. ${ }^{1}$ Several hundred different immobilizers are available today. ${ }^{2}$ No classification system for closed treatment of spine injuries exists. This new uniform and validated classification for external immobilization of the cervical spine is clinically relevant to improve communication and treatment of patients with cervical spinal injury. Furthermore, with this new validated classification system, it is possible to group external treatment modalities of the cervical spine and to compare their effectiveness and clinical outcomes with other conservative and surgical treatments. This classification is fundamental for better evidence-based treatment of cervical spine injuries in the future.

\section{Summary and Conclusion}

- The classification system for external cervical spine immobilization devices, based on anatomical support areas, has an excellent interobserver and intraobserver agreement with Fleiss' kappa values of 0.88 and 0.91 , respectively.

- Around $96 \%$ of the participating clinicians considered the classification for external cervical immobilizers to be clear.

- After using the classification system, all observers considered the classification system to be useful in clinical practice.

- With this validated classification system for external cervical immobilizers, it is possible to compare different treatment-options for cervical spine injuries, essential for future evidence-based practice and research.

\section{Conflict of Interest}

No funds or grants were received in support of this work. No benefits in any form have been or will be received from a commercial party related directly or indirectly to the subject of this article.

\section{References}

1 Fredø HL, Rizvi SAM, Lied B, Rønning P, Helseth E. The epidemiology of traumatic cervical spine fractures: a prospective population study from Norway. Scand J Trauma Resusc Emerg Med 2012; 20:85-85

2 Agabegi SS, Asghar FA, Herkowitz HN. Spinal orthoses. J Am Acad Orthop Surg 2010;18(11):657-667

3 Urbaniak GC, Plous S. Research Randomizer Form v4.0 2011. http://www.randomizer.org. Accessed March 2, 2011

4 Landis JR, Koch GG. The measurement of observer agreement for categorical data. Biometrics 1977;33(1):159-174 


\section{Editorial Perspective}

This paper was found to be interesting and technically wellperformed by most reviewers, who nonetheless questioned the real need for this study. That said, the authors made a cogent point that the use of collars, and the clinical science in terms of actual usefulness of collars is quite lacking, and therefore a more structured approach as part of a broader evaluation of collar use and their limitations would seem in order. Hopefully, the authors or EBSJ readers will be inspired to look at a more structured approach in terms of validating the use of cervical collars in more general terms. 